\title{
BMJ Global Health Integrated health system strengthening can generate rapid population impacts that can be replicated: lessons from Rwanda to Madagascar
}

To cite: Bonds MH, Rich ML. Integrated health system strengthening can generate rapid population impacts that can be replicated: lessons from Rwanda to Madagascar. BMJ Glob Health 2018;3:e000976. doi:10.1136/ bmjgh-2018-000976

Handling editor Seye Abimbola

Received 25 May 2018

Accepted 1 September 2018

Check for updates

(c) Author(s) (or their employer(s)) 2018. Re-use permitted under CC BY-NC. No commercial re-use. See rights and permissions. Published by BMJ.

Global Health and Social Medicine, Harvard Medical School, Boston, Massachusetts, USA

Correspondence to

Matthew H Bonds;

mhb9@hms.harvard.edu
At the turn of the century, the Millennium Development Goals (MDGs) set targets to dramatically improve human welfare by 2015 . These ambitious aims included reducing extreme poverty by $50 \%$, under- 5 mortality by $66 \%$ and maternal mortality by $75 \%$, and were accompanied by international support. Now, most African countries have international funding and policy commitments to treat HIV, tuberculosis (TB) and malaria, provide contraceptives to women, vaccines for children, and implement WHO-recommended treatment guidelines for maternal and child health, supported by front-line community health workers (CHWs).

Why then, if the treatments are known, affordable at scale and supported by standard policies, did only a few countries achieve their health-related MDGs and what does that mean for the prospects of the Sustainable Development Goals? One answer is that even simple technologies require complex delivery systems-a value chain of staff, stuff, systems and space-to align at the point of care and serve each individual patient. The recognition of this challenge has led to a growing movement towards health system strengthening (HSS) based on WHO's six building blocks-personnel, supplies, finance, leadership, services and information systems.

Those who see the global health challenge primarily through the lens of scale-including policymakers, international stakeholders and social ventures-point out that the HSS building blocks do not actually guide implementers, as they consist of many dimensions that are difficult to prescribe. ${ }^{1}$ The result is an enduring tendency for the international community to invest in uncoordinated vertical efforts, often undermined by challenges with integration into local health systems that are unable to adequately support them. ${ }^{2}$ Such vertical approaches can be easily measured through process indicators (such as quantity of services delivered), but rarely demonstrate population-level impacts such as on coverage or mortality rates. ${ }^{4}$

In contrast, an alternative paradigm is to integrate HSS initiatives with clinical programmes at multiple levels of the system within a geographically targeted unit. While these have traditionally lacked a strong evidence base, two recent papers in BMJ Global Health show that rapid and rigorously evaluated population-level impacts can result from HSS in different political and economic contexts. $^{56}$

In 2005, when the non-governmental organisation (NGO), Partners In Health (PIH), began working in Eastern Rwanda, the country was recovering from the 1994 genocide, when as many as a million people were killed. In the catchment area of Southern Kayonza and Kirehe districts, there was no hospital for a population of 400000 people. Under-5 mortality rate was 230/1000. Patients needing life-saving medicine had as few options as those in rural Madagascar a decade later. In coordination with Rwanda's national policies, including its Vision 2020 (established in 2007), PIH and the Government of Rwanda rapidly strengthened an integrated local health system by constructing and staffing hospitals, supporting health centres and equipping a network of CHWs that provided maternal and child health, TB and HIV care.

Rwanda has since become among the world's top performers on the health-related MDGs, and a leader in health system transformation. ${ }^{78}$ Macroeconomic drivers are clearly a factor. After the genocide, Rwanda experienced a virtuous cycle of political stability, international investment and foreign aid. 
Corruption perception and Doing Business rankings rose to among the highest in sub-Saharan Africa. ${ }^{9-11}$ Gross domestic product growth became among the top 10 in the world. Meanwhile, the president, a former military general, invested in and enforced aggressive health policies, including requiring all citizens to purchase health insurance. $^{8}$

International partnerships, such as with PIH (which was the largest health NGO in Rwanda), were an inextricable part of this progress. For both sovereignty and efficiency, these partnerships were managed centrally on terms largely defined by the Rwanda government. To understand the impacts of the HSS initiative in Rwanda, Thomson et a $a \tilde{l}$ analysed cross-sectional household-level Demographic and Health Survey (DHS) data in 2005 and 2010, within the PIH catchment area in comparison with the rest of rural Rwanda. The results show rapid improvements in population health at a subnational level: under-5 mortality dropped by $64 \%$ in 5 years; this is equivalent to an annual decrease of $12.8 \%$, which was substantially faster than the rest of rural Rwanda and triple the rate needed to meet the MDGs. But is that replicable?

In 2014, a collaboration between the NGO PIVOT and the government of Madagascar started a district-level model health system for the country based on transferring lessons primarily from PIH-Rwanda. ${ }^{6}$ As in Rwanda, the Madagascar initiative focused on the implementation of national policies at all levels of a district health system (community, health centres and hospital) to ensure a continuum of care for all patients. This included both improved readiness (such as infrastructure, staffing, training and supply chain) at each level of the system, and integrating clinical programmes, such as maternal and child health. The data systems that were ultimately retrofitted in PIH-Rwanda were improved and more carefully integrated at the outset in Madagascar.

A longitudinal cohort of a representative sample of households within and outside of the initial PIVOT catchment relied on the same instruments and field teams as the national DHS, with similar results as in Rwanda: under-5 and neonatal mortality in the PIVOT catchment area dropped by nearly $20 \%$ and $36 \%$ in the first 2 years (twice the rates required to meet the MDGs). Deliveries in health facilities increased by $63 \%$. In Madagascar as in Rwanda, per capita costs were between US $\$ 25$ and US\$35 annually.

The power of these results rests partly in the similarities at baseline between the study areas in Rwanda and Madagascar. Both countries were francophone with largely subsistence agricultural economies. Per capita income in 2005 in Rwanda was US\$430, and Madagascar in 2014 it was US\$408 (comparison done in year 2000 dollars). Under-5 mortality in Ifanadiana district in 2014 (where PIVOT started) was $145 / 1000$, and in rural Rwanda it was 158/1000 in 2005. But while Rwanda has been a top economic performer over the past two decades, Madagascar has been in economic stagnation or decline. Unlike Rwanda, whose government has become immutable, Madagascar's government suffered another coup d'état as recently as 2009 , with high government turnover and a high perception of corruption. ${ }^{12}$ Yet, despite the different political and economic contexts, the interventions generated similar results.

The results of the Rwanda study tell a story of convergence in rapid improvements between intervention (PIH catchment area) and comparison sites (rest of rural Rwanda, which itself was changing fast) over 5 years. In contrast, in Madagascar, where the PIVOT intervention was still nascent after 2 years with many programmes yet to be fully implemented, there was divergence between intervention and comparison sites (ie, the intervention area had clear improvements over the rest of the district).

While the specific process for strengthening a local health system must be adapted to the context, the core strategies presented here are based on common principles: (1) working within the public system in partnership with governments and communities; (2) addressing all building blocks of HSS to improve horizontal readiness and integrating clinical services anchored in primary care; (3) investing in capacity building throughout the system; (4) ensuring data systems that allow for impact evaluation, information loops and research with academic partners; and (5) a long-term commitment to strengthening a public system whose needs will evolve over time.

Governments and international stakeholders are still asking whether universal health coverage through community-based HSS can be replicated. In fact, such replication is occurring widely around the world. This includes PIH sites in Malawi, Mexico, Peru, Haiti and elsewhere. Essential elements have also been adapted and expanded by like-minded field-based organizations in collaboration with committed national governments in Mali (Muso), Togo (Integrate Health), Nepal (Possible), Liberia (Last Mile Health) and Kenya (Lwala) ${ }^{13}$ In periurban Mali, drops in under-5 mortality rates were especially rapid ${ }^{14}$ with results that are broadly consistent with recent evidence of health outcomes from the Millennium Villages Project. ${ }^{15}$

The evidence is now clear that the health-related SDGs can be accomplished through interventions that are integrated locally. The important questions now have to do with the process of implementation and how to best scale from the local to the national level. It is time to stop asking whether or not these initiatives can be replicated. With improved data systems that are integrated locally and amplify the evidence internationally, let us instead invest in finding the answers to how to scale them faster.

Acknowledgements This article is based on work by the governments of Rwanda and Madagascar, and the nongovernmental organizations, Partners In Health and PIVOT.

Contributors MHB and MLR conceptualised and wrote this article.

Funding The authors have not declared a specific grant for this research from any funding agency in the public, commercial or not-for-profit sectors.

Competing interests This is an editorial that discusses results of separate articles in BMJ Global Health, of which MHB and MR are coauthors. MHB and MR have also been directly engaged in the implementation of programmes discussed in this editorial. 
Patient consent Not required.

Provenance and peer review Not commissioned; externally peer reviewed.

Data statement There is no data presented for this editorial -which is a secondary comment about other research articles. The relevant data sharing statements are provided in those articles.

Open access This is an open access article distributed in accordance with the Creative Commons Attribution Non Commercial (CC BY-NC 4.0) license, which permits others to distribute, remix, adapt, build upon this work non-commercially, and license their derivative works on different terms, provided the original work is properly cited, appropriate credit is given, any changes made indicated, and the use is non-commercial. See: http://creativecommons.org/licenses/by-nc/4.0/

\section{REFERENCES}

1. Marchal B, Cavalli A, Kegels G. Global health actors claim to support health system strengthening: is this reality or rhetoric? PLoS Med 2009;6:e1000059.

2. Institute for Health Metrics and Evaluation. Financing global health 2016: development assistance, public and private health spending for the pursuit of universal health coverage, 2017.

3. Swanson RC, Cattaneo A, Bradley E, et al. Rethinking health systems strengthening: key systems thinking tools and strategies for transformational change. Health Policy Plan 2012;27:iv54-61.

4. Pai M, Schumacher SG, Abimbola S. Surrogate endpoints in global health research: still searching for killer apps and silver bullets? BMJ Glob Health 2018;3:e000755.
5. Thomson DR, Amoroso C, Atwood S, et al. Impact of a health system strengthening intervention on maternal and child health outputs and outcomes in rural Rwanda 2005-2010. BMJ Glob Health 2018;3:e000674.

6. Garchitorena A, Miller AC, Cordier LF, et al. Early changes in intervention coverage and mortality rates following the implementation of an integrated health system intervention in Madagascar. BMJ Glob Health 2018;3:e000762.

7. Binagwaho A, Farmer PE, Nsanzimana S, et al. Rwanda 20 years on: investing in life. Lancet 2014;384:371-5.

8. Abbott P, Sapsford R, Binagwaho A. Learning from success: how Rwanda achieved the millennium development goals for health. World Dev 2017;92:103-16.

9. The World Bank Group. Doing Business 2010: Reforming through difficult times". Washington: The World Bank, 2009.

10. The World Bank Group, 2018. World bank open data. https://data. worldbank.org

11. Transparency, International. Corruption perception index 2010, 2010

12. Transparency, International. Corruption perception index 2016, 2016.

13. Ballard M, Schwarz R, Johson A, 2017. Practitioner expertise to optimize community health systems: Harnesssing operational insight. https://www.chwimpact.org

14. Johnson $A D$, Thiero $O$, Whidden $C$, et al. Proactive community case management and child survival in periurban Mali. BMJ Glob Health 2018;3:e000634.

15. Mitchell S, Gelman A, Ross R, et al. The Millennium Villages Project: a retrospective, observational, endline evaluation. Lancet Glob Health 2018;6:e500-e513. 